JOANNA MROCZKOWSKA D https://orcid.org/0000-0003-0741-2895

Instytut Archeologii i Etnologii PAN

\title{
Jedzenie regionalne, lokalne czy "swoje" - tożsamościowy wymiar praktyk jedzeniowych na Podlasiu
}

$\mathrm{W}$

artykule ${ }^{1}$ stawiam pytanie o związek jedzenia oraz praktyk jedzeniowych z tożsamością podlaskich mieszkańców wsi. W podejściu teoretycznym moje rozważania wpisują się w subdyscyplinę antropologii jedzenia, która zakłada namysł nad społecznymi i kulturowymi aspektami konsumpcji i produkcji jedzenia. W szczególności podążać będę śladami Marshalla Sahlinsa, który w ten sposób pisał o więziotwórczej roli jedzenia:

Jedzenie jest życiodajne, nieodzowne i zwyczajowo symbolizujące domowe ognisko, dom, a nawet matkę. W porównaniu z innymi materiami jedzenie dzielone jest najchętniej i najłatwiej (...), wymiana jedzenia jest czułym barometrem relacji społecznych - jedzenie można więc wykorzystywać przedmiotowo, by nawiązać, podtrzymać bądź zaburzyć relacje (Sahlins 1972: 215-216, tu i dalej tłumaczenie własne).

\footnotetext{
${ }^{1}$ Tekst ten opiera się na badaniach prowadzonych przeze mnie na Podlasiu w latach 2010-2016. Metodą badań była obserwacja uczestnicząca (Clifford 2000: 42) i półstrukturyzowane wywiady prowadzone w społecznościach lokalnych na terenie Dąbrowy Białostockiej i okolicznych wsi, wśród ludności katolickiej i prawosławnej. Przytaczane w artykule cytaty pochodzą z wywiadów przeprowadzonych przeze mnie w ramach projektu NCN 172028 ,Kulturowe i społeczne aspekty konsumpcji i produkcji żywności w społecznościach lokalnych w świetle najnowszych zmian geopolitycznych. Monografia etnograficzna okolic Dąbrowy Białostockiej" oraz $\mathrm{z}$ wywiadów nagranych przez prowadzoną przeze mnie studencką grupę badawczą $\mathrm{w}$ ramach zajęć Laboratorium etnograficzne „Kulturowe aspekty konsumpcji i produkcji jedzenia. Etnografia okolic Dąbrowy Białostockiej”, finansowanego przez Instytut Etnologii i Antropologii Kulturowej Uniwersytetu Warszawskiego.
} 
Z kolei praktyki jedzeniowe rozumiem poprzez pojęcie foodways, które w szerokim znaczeniu odnosi się do relacji pomiędzy zachowaniami i czynnościami związanymi z jedzeniem oraz sposobami uczestnictwa w danej wspólnocie. Jak pisał Charles Camp: „W najbardziej ogólnym znaczeniu foodways odnosi się do systemu wiedzy i ekspresji związanego z jedzeniem, takiego, który jest specyficzny dla danej kultury" (Camp 2003: 29). W odpowiedzi na pytanie o związek jedzenia i tożsamości, w szczególności tej dotyczącej poczucia zakorzenienia i więzi z miejscem, kluczowe będą także takie kategorie jak: „lokalny”, „regionalny”, ,tutejszy”, "swój”. W literaturze przedmiotu są one często łączone z pojęciami tożsamości regionalnej, tożsamości lokalnej czy swojskiej (por. np. Waszczyńska 2014). Celowo nie posługuję się tymi rozróżnieniami. W artykule pragnę pokazać, po pierwsze, że takie poziomy tożsamości przeplatają się ze sobą. Po drugie, twierdzę, że tożsamość ma dyskursywno-performatywny charakter, a jej podstawową cechą, łączącą wszystkie poziomy, jest szczególna relacja z miejscem, właściwa dla osób związanych z rolnictwem, których praca, życie i jedzenie wpisane jest w pewną przestrzeń.

By zrozumieć tak tworzącą się tożsamość, proponuję pojęcie terroir, które pierwotnie odnosiło się do związków przestrzeni, środowiska, gdzie warunki geograficzne wpływają na specyficzny smak lokalnych produktów (oryginalnie wina i serów). Termin ten jest ugruntowany w wielu naukach społecznych, w tym antropologii, a jego definicja ewoluowała, by obecnie „łączyć ze sobą aktorów, ich historie, formy społecznego organizowania się, a co najważniejsze ich praktyki rolnicze" (Bérard, Marchenay 2005; cyt. za Demosier 2011: 686). Tym samym więc terroir jest pewnym powiązaniem ludzi, przestrzeni, przyrody ożywionej i nieożywionej w taki sposób, by wytworzyć specyficzny dla danego miejsca smak. Terroir można więc rozumieć jako smak, który nadany jest jedzeniu poprzez właściwości gleby, warunki pogodowe, ale też specyficzne techniki pracy człowieka czy zwierząt. I właśnie taka wspólnota smaku wynikająca z lokalności jest, co pragnę pokazać w tym tekście, podstawą tożsamości terroir.

Zaproponowanie terminu „,tożsamości terroir" w celu spojrzenia na tożsamość w sposób niewymuszający rozdzielania poziomów, np. regionalnego od lokalnego, jest tym bardziej przydatne, że pojęcia regionalności, lokalności, tutejszości i swojskości bywają rozmaicie, i płynnie używane przez moich rozmówców: niekiedy jako kategorie emiczne, czasem jako świadome, a nawet pragmatyczne odwołanie się do dyskursów medialnych czy instytucjonalnych. I tak na przykład kategorie te są obecnie wykorzystywane jako element strategii pozyskiwania finansowania na inwestycje lokalne, jako element miejscowych polityk czy gier wizerunkowych ${ }^{2}$.

Struktura artykułu wynika z konieczności przedstawienia różnych obszarów tworzenia się tożsamości terroir. Po pierwsze, pokazuję, w jaki sposób kategorie

\footnotetext{
${ }^{2} \mathrm{O}$ podobnym procesie pisali Aleksandra Kleśta-Nawrocka i Rafał Kleśta-Nawrocki, którzy pokazali, w jaki sposób konstrukt, jakim jest dziedzictwo kulinarne (w tym przypadku kuchnia mennonicka), bywa rozgrywane $\mathrm{w}$ gęstej sieci zależności tworzonych przez podmioty lokalne (Kleśta-Nawrocka, Kleśta-Nawrocki 2016: 157-172).
} 
jedzenia regionalnego i lokalnego są konstruktami i jako takie kształtują tożsamość, ale też tożsamość tych społeczności kształtowana jest przez ten konstrukt. Po drugie, analizuję inne lokalnie używane kategorie służące do opisania więzi z miejscem, ze społecznością, jak również zastanawiam się nad tym, w jaki sposób praktyki jedzeniowe postrzegane są jako zmienne w czasie. W kolejnej części przedstawiam zaś różne produkty i praktyki jedzeniowe, które są kluczowe dla tożsamości terroir, choć bywają przezroczyste nawet dla członków tych społeczności. Moim celem jest pokazanie, że nie tylko region, lokalność czy wieś są ważnymi punktami odniesienia określającymi tożsamość, ale przede wszystkim są to relacje ludzi, jedzenia i przestrzeni manifestujące się w pojęciu „swojego”, w szczególności zaś w poczuciu wspólnego „swojego smaku”.

\section{Jedzenie regionalne i lokalne jako konstrukt}

Prasa, literatura popularna i ogólnie media propagują określoną wizję jedzenia regionalnego czy lokalnego. Wpływa to niejako odgórnie na to, jak rozumie się jedzenie regionalne wśród mieszkańców podlaskich wsi i miasteczek. Jak zauważyła historyczka jedzenia Rachel Laudan (2001), w popularnych książkach kulinarnych, opisujących fenomen jedzenia regionalnego, podkreśla się bogactwo i różnorodność takich kuchni, a także to, że wpływają na zachowanie dobrego zdrowia. Tym samym dochodzi do pewnego (często świadomego) zamazania rzeczywistości - nie wszystkie kuchnie regionalne były bogate, różnorodne czy zdrowe. Badaczka zwróciła uwagę, że w niektórych opisach potraw czy kuchni określanych mianem regionalnych pojawiają się wzmianki o służących przygotowujących jedzenie, o podróżach, restauracjach i turystyce. Są to napomknienia, które wskazują na to, że dania, opisywane jako kuchnia „tradycyjna” czy „regionalna", są w dużej mierze kuchnią warstw zamożnych ${ }^{3}$.

Laudan pisze, i częściowo ma to również odniesienie do polskiej kuchni, że jedzenie "regionalne” było najczęściej "skąpe i monotonne” (Laudan 2001: 42). Gloryfikujące je opisy najczęściej czerpią, w przypadku Polski, z kuchni ziemiańskiej, ewentualnie z kuchni najzamożniejszych warstw chłopstwa. Już na tym poziomie widać, że to, co uważane jest w dyskursie medialnym, potocznym, a także lokalnym za kuchnię regionalną, jest konstruktem kulturowym. „Regionalne" może odzwierciedlać bowiem często kuchnię tylko jednej (bogatszej) warstwy społecznej. Ponadto sytuację komplikuje fakt, że dochodzi do sprzężenia zwrotnego, w którym kuchnia opisywana jako regionalna wtórnie staje się inspiracją dla społeczności lokalnych, a z czasem również wyznacznikiem ich tożsamości, np. tożsamości terroir. Przyjmuję więc, że kuchnia regionalna jest konstruktem, wokół którego narosły liczne stereotypy.

\footnotetext{
${ }^{3} \mathrm{Na}$ temat tworzenia tożsamości regionalnych poprzez książki kulinarne powstał kluczowy w studiach jedzeniowych artykuł Arjuna Appaduraia (1988). W moim tekście koncentruję się jednak głównie na perspektywie oddolnej, stąd nie odwołuję się bezpośrednio do propozycji badawczych tego autora.
} 
Według Laudan jednym z często wyrażanych sądów w dyskursie medialnym przez piewców kuchni regionalnej jest podkreślenie, że jest ona bardziej zróżnicowana i zdrowsza od tłustej i zbytkownej kuchni warstw zamożnych. Tworzenie takiego stereotypu prawdopodobnie ma długą historię. W odniesieniu do kontekstu polskiego interesujące jest to, co napisano o wydanej w 1842 roku książce Jana Milikowskiego, pt. Nowy, wyborny i najtańszy kucharz, mającej ukazać, jak bardzo zróżnicowana może być tania kuchnia warstw niezamożnych. W książce tej zostały zmieszczone setki przepisów na dania z ziemniaka: rozmaite jarzyny, wypiekanki, leguminy, ziemniaki używane do wyrobu piwa, wina, kawy, mydła itp. Wojciech Józef Burszta i Waldemar Kuligowski trafnie podsumowali jej przekaz, demistyfikując i dekonstruując jednocześnie rzeczony stereotyp:

Brzmi to przemyślnie, (...) ale nie zmienia to faktu, że codzienną podstawą pozostają ziemniaki - i tylko one! Ziemniaki rano, ziemniaki w południe, (...) ziemniaki w dzień powszedni, ziemniaki od święta, ziemniaki do jedzenia, ziemniaki do picia, (...) ziemniaki ad infinitum (Burszta, Kuligowski 2005: 118).

Przeświadczenie o tym, że kuchnia lokalna jest mało zróżnicowana i uboga w składniki wyrasta, moim zdaniem, z podobnych przekonań. $\mathrm{W}$ obu przypadkach konstruowana jest ona przez środowiska inne aniżeli sami rolnicy/społeczności lokalne, przez co stanowi uproszczone wyobrażenie grupy przeświadczonej o swej kulturowej wyższości na temat innej grupy. Media przedstawiające jedzenie lokalne jako zróżnicowane i zdrowe mityzują wieś jako ostoję „,autentyczności”, ,zdrowia” i „bliskości z naturą", choćby i wynikającej z prostoty czy biedy. Kultura lokalna i regionalne jedzenie stają się ponownie obiektem spojrzenia "z góry", tym razem z misją cywilizacyjną, a czasem także z protekcjonalną oceną ubogiej diety opartej na ziemniaku.

Tak więc w odniesieniu do jedzenia lokalnego czy regionalnego należy uwzględnić kulturowe konteksty definiowania tych pojęć i nie nakładać nieprzystających kategorii na opisywany (europejski, polski) kontekst. Maria Fonte (2008) wyróżniła dwa sposoby definiowania jedzenia lokalnego: północnoamerykański (USA i Kanada) i europejski. W tym pierwszym rozumieniu jedzenie lokalne uwarunkowane jest „politycznymi interesami opierającymi się przemysłowemu systemowi produkcji jedzenia i ukierunkowanymi na utworzenie alternatywnej gospodarki produkcji żywności opartej na zasadach sprawiedliwości społecznej i ekologicznej równowadze" (Fonte 2008: 201). Natomiast w perspektywie europejskiej lokalne jedzenie ma na celu głównie „włączenie w rozwój ekonomiczny małych firm, gospodarstw wiejskich i niszowych gospodarek agrykultury" (Fonte 2008: 201). Jedzenie lokalne może być więc rozumiane na wiele sposobów: często jest ono antynomią jedzenia globalnego; kojarzone jest na przykład $\mathrm{z}$ jedzeniem slow, a tym samym stawiane w opozycji do fast foodów (por. Egan et al. 2006). Bywa również utożsamiane z jedzeniem właściwym dla mniejszości: etnicznych czy religijnych. Wspólnym dla tych różnych sposobów rozumienia jedzenia lokalnego może być trop interpretacyjny, zgodnie z którym jedzenie 
to jest zawsze odczytywane jako pewna alternatywa, coś właściwego podmiotom słabszym, mniejszym aniżeli państwo czy korporacje międzynarodowe.

\section{Kategorie emiczne a tożsamość terroir}

Zakładając, że zarówno jedzenie lokalne, jak i regionalne jest konstruktem, stawiam pytanie o rolę, jaką ten konstrukt odgrywa w tworzeniu tożsamości w społecznościach okolic Dąbrowy Białostockiej. Zadaję też pytanie o to, jakie funkcjonują inne kategorie emiczne dotyczące ,jedzenia stąd” w społeczności lokalnej i jakiego rodzaju tożsamość współtworzą.

Swoje, regionalne, tradycyjne

Istnieje kilka sposobów emicznego użycia pojęć odnoszących się do jedzenia lokalnego, które są kluczowe dla zrozumienia roli, jaką pełni ono w tworzeniu i negocjowaniu tożsamości. Pierwszy związany jest z rozumieniem kategorii jedzenia lokalnego poprzez łączenie go w narracjach rozmówców z pojęciem jedzenia "swojego" stojącego w opozycji do jedzenia „kupowanego". "Swoje” łączy w sobie wyobrażenia na temat regionu, tradycji, poczucia ciągłości, historii, religii, jak również idee swojskości, domowości i rodzinności.

Sposób mówienia o nim sugeruje, że jest ono pewną oczywistością wynikającą z wysoko wartościowanej w tej kulturze samowystarczalności (por. Straczuk 2006: 170). Poniższa wypowiedź może wydawać się truizmem, ale to właśnie w wypowiedzeniu tej pozornej oczywistości, kryje się ontologiczne zapewnienie co do właściwego porządku rzeczy:

Tutaj mamy swoje ogórki, pomidory z tunelu i ogórki. Buraczki, to przecież wszystko się ma swoje [27.07.2011, Grabowo, K47, M49]4.

Jednocześnie można zauważyć, że istnieje kluczowa komplementarność swojego i kupnego:

C: Tak, tak, ogródek jest.

M: Jest na swoje potrzeby, a jak nie ma, to się kupuje [27.07.2011, Chilmony, M, ok. 50, K, ok. 20 (ojciec i córka)].

\footnotetext{
${ }^{4}$ Rozmowy koduję w następujący sposób: [data przeprowadzenia rozmowy, (ewentualnie) miejscowość, płeć i wiek (ewentualnie relacja) rozmówców].
} 
„Swoje” wartościowane jest wyżej aniżeli jedzenie pochodzące ze sklepu, które nabywano tylko wówczas, gdy nie można go było wytworzyć samemu:

K: Wiecie, swoje zawsze lepsze. Jeszcze zależy, jak to kto przyrządzi [21.07.2011, Suchodolina, K, ok. 70, M, ok. 70].

M: No tak, troszeczkę się rozpasłem ostatnio. Ale staram się jeść rzeczy tylko swoje, nie kupowane w sklepie. Znaczy wędliny, bardzo rzadko się zdarza coś kupić [28.07.2011, M, ok. 50].

W codziennych narracjach często podkreśla się niższą rangę jedzenia kupnego w tym przypadku ma o tym świadczyć fakt, że jest ono odrzucane przez zwierzęta:

K: [Dzikom sypie się jedzenie przez cały rok.] Ale też swojskie, nie kupowane, bo kupowanych nie jedzą dziki. (...)

M: Kolega ma sklep i się zaopatruje na giełdzie warzywnej, i mówi, że załatwi mi takich z małą skazą dla dzików. I wyobraźcie sobie, że zwierzyna tego nie tknęła. A te zbierane z sadu na wiosce, to śladu nie ma [28.07.2011, M, ok. 50, K, ok. 45, mąż i żona].

Wybór smakowy, którego dokonuje (dzikie) zwierzę, zdaje się poświadczać wartość jedzenia „swojego”. Fakt, że dziki odmawiają jedzenia „kupnej” kukurydzy i jabłek, można zinterpretować, odwołując się do kategorii natury i kultury, zwierzęta te, pozostając po nieujarzmionej kulturą stronie rzeczywistości, tym bardziej zachowały „naturalną” zdolność rozpoznania smaków zdrowych, dobrych, „autentycznych”. Swoje jedzenie jest więc pewnym kodem kulturowym, a nawet komunikatem moralnym, poprzez który dokonuje się połączenie sposobu jedzenia (opartego na jedzeniu własnym, stąd, "swoim”) z tożsamością zakorzenioną w miejscu i społeczności, czyli tzw. tożsamością terroir.

Kolejnym pojęciem odnoszącym się do jedzenia lokalnego, ważnym ze względu na osadzenie w narracjach tożsamościowych terroir, jest kategoria "regionu” i związane z nim jedzenie regionalne, czasem określane mianem "tradycyjnego". Jedzenie regionalne czy tradycyjne to pojęcia używane lokalnie, które należy traktować jako hasła zrozumiałe dla każdego (choć wieloznacznie), wywołujące wśród lokalnych społeczności silne skojarzenia jedzeniowe:

R: A tutaj jakieś tradycyjne potrawy w regionie są?

K: Babka ziemniaczana. Kiszka ziemniaczana. I co jeszcze? Sękacze. To tam bliżej Suwałk, ale tu u nas, no, to pisanki u nas, tu w Lipsku bardzo występują te panie, pisanki idą za granicę, wszędzie. Te panie wożą wszędzie. Rękodzieło różne, dywany, gąski weselne. (...)

Ale jak szła panna młoda za mąż albo pan młody. Chłopak albo dziewczyna, no to dzień wcześniej były takie gąski, tak ludzie na wsiach. Taka była tradycja. Jak jutro miał być ślub, to dzisiaj już gąski rozdawali w tym domu. I przylatywały dzieci, takie małe. (...) I wychodziła panna młoda i częstowała tymi gąskami. I jak 
ja już chodziła, to były ciasteczka takie kruche pieczone. A wcześniej jeszcze jak nasze babcie i prababcie chodziły, to rzeczywiście to były gąski. (...) I to właśnie tutaj w Lipsku jedna pani to robi i też właśnie jej to rękodzieło, to idzie tam na tych wystawach różnych i wszystko, bo to przekazała jej teściowa, dla teściowej może babcia czy matka, i to już z dawna, i ona już wtajemniczona, i ona wie, jak to piec, bo to trzeba umieć przecież. (...) [16.11.2011, Jałowo, K, ok. 55].

Na pytanie o „tradycyjne potrawy” rozmówczyni zaczęła wymieniać jedzenie, które jej zdaniem należy do tej kategorii - a więc, po pierwsze, była to babka ziemniaczana - zapiekanka z ciasta podobnego do tego, z którego robi się placki ziemniaczane. Jest to danie uważane za codzienne, zwyczajne. Świadczyć o tym może fakt, że w prawie każdym domu zakupiona jest specjalna maszynka elektryczna do tarcia ziemniaków. Kobieta wspomina także o sękaczu i gąskach (pieczone bułeczki rozdawane przed ślubem; por. Olędzki 1961). Świadomie wpisuje je w kategorię „rękodzieła”, mówiąc o kobietach, które zajmują się prezentowaniem i sprzedażą rękodzieła zawodowo lub półzawodowo. Widać więc dwuznaczność rozumienia kategorii „tradycyjne pokarmy” - są to zarówno dania spożywane na co dzień, zwykłe, nieświąteczne, jak i te, które wpisywane są w oficjalne dyskursy tworzenia, podtrzymywania i odtwarzania tradycji - pokarmy związane z pewnymi rytuałami i świętami.

Pojęcie tradycji ma długą historię w naukach humanistycznych i społecznych; początkowo starano się znaleźć uniwersalną definicję. Edward Shils zaproponował na przykład: „W swoim najbardziej narzucającym się elementarnym sensie [tradycja] oznacza traditum: jest tym wszystkim, co jest transmitowane lub przekazywane z przeszłości do teraźniejszości" (Jasiewicz 1987: 355; cyt. za Shils 1981). Kazimierz Dobrowolski zaproponował zaś podobną definicję, „[p]rzez tradycję rozumiemy w zasadzie wszelką spuściznę, którą ustępujące generacje przekazują pokoleniom wchodzącym w życie" (Dobrowolski 1966: 76). Dla celów niniejszej analizy za bardziej przydatne uznaję jednak podejścia konstruktywistyczne. "Tradycję" traktuję więc jako powszechną, choć różnie rozumianą kategorię, której urok, tak jak pojęcie kultury (por. Kuper 2006: 4) ${ }^{5}$, polega na tym, że wydaje się ona zrozumiały dla każdego. Podobnie jak można stwierdzić, że każdy ma kulturę, można powiedzieć, że każdy ma swoją tradycję. Pojęcie to używane jest nie tylko, by uspójnić doświadczenie (tworzy wyobrażenie o ciągłości historycznej), ujednolica również sam odbiór komunikatu - „tradycja” wręcz uniwersalnie wartościowana jest pozytywnie. Prawie każdy również zgodziłby się co do kwestii, że tradycje należy pielęgnować/chronić/ocalić przed zapomnieniem itp. Tradycja może oznaczać wiele rzeczy, ale ludzie używający tego pojęcia będą

\footnotetext{
${ }^{5}$ Pisał on dalej o użyciu takiego pojęcia jak kultura jako pewnym wytrychu: „Politycy nawołują do rewolucji kulturalnej. Najwyraźniej potrzebna jest jakaś potężna zmiana kulturowa, by rozwiązać problemy biedy, narkomanii, bezprawia i przemysłowej konkurencyjności. Mówi się o różnicach kulturowych pomiędzy płciami i pokoleniami, drużynami piłkarskimi czy też agencjami reklamowymi. Niepowodzenie fuzji dwóch przedsiębiorstw wyjaśnia się niekompatybilnością ich kultury" (Kuper 2006: 4).
} 
mieli przekonanie, że odnoszą się do wspólnego znaczenia. Co więcej, ,tradycja”, tam gdzie prowadziłam badania, jest w społeczności przedmiotem społecznego namysłu (por. Giddens 2005).

Sami Zubaida i Richard Tapper pisali, że w dyskursie na temat kuchni (podobnie jak w nacjonalistycznych/narodowych ideologiach) istnieje tendencja postrzegania procesów w kategoriach ciągłości, ujawniają się tu wyraźnie przyjęte (często nieuświadomione) założenia o ciągłości kulturowej, poszukiwanie początków (Zubaida, Tapper, red., 1994; cyt. za Holtzman 2006: 368) i esencjalizowania wspólnoty. Taką tendencję należy sobie uświadomić, jako że jest ona również podstawową funkcją pojęcia tradycji. Wybrane dania traktuje się tak, jakby w danej kulturze występowały od jej „mitycznych początków”, od zawsze łącząc ze sobą środowisko i ludzi we wspólnocie smaku i tożsamości terroir. Inne z kolei opisywane są w sposób tworzący dystans: podkreślając różnicę, ludzie oddzielają się od innych regionów, definiują swoją tożsamość, która ma się opierać na wyobrażonej ciągłości wzorów jedzenia:

K: Zupę grzybową czasami robię, aczkolwiek każdy weźmie po łyżce, tylko symbolicznie. Jako regionalne nie jest przyjęte, ani karp, ani zupa grzybowa.

M: Karpia nikt nie chce zabić.

K: Karpia nikt nie lubi, ale przede wszystkim nie ma tradycji jedzenia karpia na Podlasiu. Tutaj ta ryba uchodzi za niesmaczną, mulastą taką. My robimy rybę po grecku, faszerowaną, przeważnie pstrąga [21.07.2011, Ostrowie, K, ok. 50, M, ok. 22 (matka i syn)].

Samo zadanie pytania o praktyki związane z „tradycją" sprawia, że identyfikuje się doxę, rozumianą jako niekwestionowane praktyki (Bourdieu 1972: 164). Jest to moment ujawnienia doxy, który jednocześnie ustanawia dyskursy innych współzawodniczących ortodoksji (karpia tutaj nikt nie lubi). Na przykład hasło „tradycyjne” wywołuje skojarzenia „zacofania”, a także „ekologiczności”, „zdrowia" - to są właśnie współzawodniczące ze sobą dyskursy, które w tej społeczności istnieją, a które można otworzyć „kluczem”, jakim jest pojęcie „tradycyjne”. Jednocześnie „tradycja” w odniesieniu do jedzenia jest czymś niezwykle plastycznym i elastycznym, jest ona z łatwością tworzona. Jak pisała Theresa Preston-Werner: „Wraz z tym jak kolejne pokolenia następują po sobie, dawne sposoby jedzenia (foodways) odpływają w niepamięć i zastępowane są przez nowe tradycje i wynalezione poczucia bliskości (invented familiarities)" (Preston-Werner 2009: 24).

\section{Jedzenie wschodnie i podlaskie}

Tożsamość terroir można analizować też z innej perspektywy, a mianowicie - perspektywy regionu jako pewnej części Polski, kraju. Lokalni mieszkańcy, definiując siebie oraz specyfikę relacji i przestrzeni, w których funkcjonują, używają takich pojęć jak „Wschód”, „Podlasie”, a nawet „Polska B”. Nie są to, moim zdaniem, dla 
nich terminy emocjonalnie neutralne. Te kategorie są inne niż ogólne i bardziej neutralne pojęcia regionu i tradycji. Tożsamość terroir wynika również z takiego związku jedzenia i przestrzeni. Teren opisywany poprzez pojęcia podlaskości czy Wschodu jest definiowany przez zamieszkujących go ludzi również poprzez szczególną produkcjęjedzenia. Poniżej przedstawiam wybrane przykłady wypowiedzi:

K: Na Boże Narodzenie na Podlasiu najważniejszą potrawą to jest kutia. Kupujemy pęczak z pszenicy, gotujemy, do tego dodaje się mak, którego Mirek [mąż rozmówczyni] nie cierpi, i wszystkie bakalie - rodzynki, orzechy, miód. Jak do zjedzenia od razu, to bardzo dobre jest [21.07.2011, Ostrowie, K, ok. 50].

M: Ogólnie ta wschodnia wieś, tutaj wschodnie strony to i to tak jest naprawdę tak ekologiczne uprawy, że głowa mała (...), tam tych hektarów nie dużo, mały, cztery-pięć, ogólnie to jest działka. Nawozów ogólnie się nie używa [23.07.2011, Harasimowicze, K, ok. 50, M, ok. 55].

Ludzie, podkreślając odmienność warunków produkcji jedzenia, używają też sformułowania, że „Podlasie to Zielone Płuca Polski, na Podlasiu jest mniej takich większych gospodarstw, są raczej takie mniejsze i takie średnie?" [23.07.2011, Harasimowicze, K, ok. 50, M, ok. 55]. Można więc powiedzieć, że takie kategorie jak podlaskość, tutejszość czy lokalność konceptualizowane są również poprzez szczególny sposób przygotowania, ale też produkcji jedzenia (uprawy roślin czy hodowli zwierząt), odmienny od pozostałych części kraju.

Podobnie jest ze smakowymi upodobaniami, które wyjaśniane są właśnie poprzez zakorzenienie lokalne, przynależność do postrzeganej terroir wspólnoty smaku. Jak tłumaczyła jedna z rozmówczyń:

C: (...) Mąż nie cierpi babki ziemniaczanej, a my uwielbiamy, bo u niego nie ma tego zwyczaju absolutnie. (...)

Z: Bo to jest wschodnie danie! (...)

C: Tak, zawsze mi marnuje danie [26.07.2011, Jasionówka k., K, ok. 50, M, 50].

Pojęcie wschodniego jedzenia legitymizuje także różnice preferencji smakowych, w których, choć dostrzega się element indywidualny, to jednocześnie wpisuje się je w szersze podziały pomiędzy regionami, częściami Polski itp. W tym przypadku niechęć męża do babki ziemniaczanej jest jednocześnie podstawą do wykluczenia go z pewnej wspólnoty „mieszkańców wschodnich ziem”.

\section{Negocjowanie kategorii i tożsamości terroir}

To, co uważane jest za stałe, ciągłe, tradycyjne, bywa także kwestionowane w opisywanej społeczności. Analiza treści internetowych umożliwia zastanowienie się nad procesem negocjowania kategorii określających związek jedzenia, człowieka 
i jego miejsca (a nawet podawania w wątpliwość tej kategorii). Przykłady można znaleźć w burzliwych wymianach zdań odbywających się w blogosferze. Na cytowanym blogu kulinarnym Smakotyk poświęconym kuchni miejscowej toczy się wiele ciekawych dyskusji na temat tego, czym jest kuchnia lokalna, regionalna czy podlaska. Tych kwestii dotyczą najbardziej gorące debaty - liczba komentarzy rośnie zawsze, gdy zamieszczany jest przepis na danie, które przez moich rozmówców określane było jak "stąd”. Na przykład pod przepisem i opisem babki ziemniaczanej miała miejsce dynamiczna wymiana zdań, którą przytoczę w obszerniejszych fragmentach, ponieważ pokazuje ona dobitnie, w jaki sposób negocjowana i wytwarzana jest wiedza na temat tego, co uznawane jest za kuchnię regionalną. Jeden z komentujących blogerów pisał w ten sposób o „,autentycznym" pochodzeniu babki ziemniaczanej:

Podczas ostatniej wizyty w Mińsku na Białorusi (restauracja Rakuskij Browar polecam) poprosiłem kucharza o informację jaka potrawa jest najbardziej charakterystyczna dla kuchni białoruskiej, odpowiedź była taka: - nie istnieje kuchnia białoruska, jest tylko zlepek wpływów rosyjsko-litewsko-polsko-ukraińskich i tyle.

Zresztą babka ziemniaczana na Białorusi jest zapiekana w naczyniach glinianych $z$ dodatkami (...) a nie na blasze tak jak w Polsce. Proszę sprawdzić pochodzenie babki w źródłach historycznych : otrzymamy informację że jest to potrawa pogranicza polsko-litewskiego a informacja o białoruskości tej potrawy jest błędna i powstała z powodu błędnego skojarzenia najczęstszego występowania po II wojnie babki na obecnych terenach Białorusi ukradzionych nam przez stalina w 1945 Czyli reasumując babka ziemniaczana nie jest potrawą białoruską ${ }^{6}$ [pisownia oryginalna tu i dalej].

Prowadząca blog odpowiedziała pojednawczo:

Być może kucharz nie był Białorusinem i nie miał pojęcia o pochodzeniu dań, które serwuje w swojej restauracji :) W „Kuchni białoruskiej” z 1984 r czytamy:, Kuchnia białoruska ma wielowiekową, bardzo bogatą historię. Jej wpływ zaznaczył się w różnym stopniu w kuchniach sąsiednich narodów: Rosjan, Ukraińców, Polaków, Litwinów i Łotyszów. (...) Szczególne miejsce w kuchni białoruskiej zajmują ziemniaki. Z masy z ziemniaków, gotowanych i surowych, w połączeniu z innymi produktami sporządza się mnóstwo samodzielnych dań: placki, oładki, BABKI, kluski, pierogi i zapiekanki." (...) O białoruskości babki ziemniaczanej mówi też Mikołaj Rey w swoim programie kulinarnym." Czyli reasumując jest jednak kuchnia białoruska i babka ziemniaczana jest potrawą białoruską. Pozdrawiam!

${ }^{6}$ Zob. https://isokolka.eu/blogi/154-smakolyk/7462-babka-ziemniaczana-blog [dostęp: 19.11.2020]. 
Jak widać, autorka próbowała powołać się na autorytet słowa pisanego i mówionego bez odpowiedniej dozy krytycyzmu. Fakt znalezienia wzmianki o istnieniu „kuchni białoruskiej” miał potwierdzać istnienie tego zjawiska. Jednocześnie brak wiedzy szefa kuchni próbowała tłumaczyć przypuszczalną, inną aniżeli białoruska, narodowością tegoż. Tak jakby sama narodowość oznaczać miała automatycznie „wiedzę o pochodzeniu potraw”.

Daje się jednak zauważyć krytycyzm uczestnika dyskusji wobec źródeł pisanych:

W wielu książkach kucharskich istnieje przepis na babkę ziemniaczaną co nie oznacza że należą one do kuchni tych narodów w których książkach się znajdują więc to bardzo naciągany dowód (patrz: ryba po grecku albo karp po żydowsku) a powoływanie się na książkę kucharską z czasów komunistycznej Białorusi to już kulinarny faux paux!!

Jak chce się pisać o historii potraw nie tylko o potrawach wypadałoby ruszyć 4 litery z kuchni i poszperać w źródłach historycznych o pochodzeniu tematów i przedmiotów o których próbuje się opowiadać a nie po prostu powtarzać błędne stereotypy. Nie wypada to twórcy kulinarnego blogu o historii kuchni naszego regionu. Proszę nie okłamywać ludzi bo większość nie ma pojęcia o historii i za pani błędną drogą podążą w złym kierunku (szczególnie młodzież która naprawdę może pomyśleć że babka jest białoruska tak jak Hajnówka i Wilno). Wstyd....

W innym miejscu ta sama komentatorka Naomi pisze:

Co do naszej podlaskiej kuchni to cytuję wstęp do książki Andrzeja FiedorukaKuchnia podlaska w rozhoworach i recepturach opisana $>$...Kuchnia Podlasia? Wielu westchnie, że tylko kiszka i pyzy. (...) Historycy i lokalni patrioci poszukiwać będą granic owego Podlasia. Ja zaś twierdzę, że to cudowna kuchnia tworzona przez lata w mozaice narodów, kultur i religii. W dymie z kominów wiejskich chałup, przycupniętych pod lasami, w zapachu chleba i siana. W szlacheckich dworkach, mieszczańskich kamienicach i żydowskich karczmach. Tworzona przez sąsiadów a czasami i wrogów. (...) Gdzie powiedzenie Gość w dom Bóg w dom, nie było przyczynkiem do wielodniowej pijatyki ale nabierało właściwego wymiaru...< Dlatego chyba jej walory smakowe są tak bogate jak nasza podlaska historia :)

Wspólna kategoria „naszego”, „Wschodniego” ma godzić te różne oglądy na to, czym jest narodowość kuchni oraz jaki rodzaj autorytetu jest konieczny, by taką kuchnię uprawomocnić:

Nieważnie czy to jest danie białoruskie, polskie czy też litewskie bo jest to przede wszystkim dnie typowo wschodnie czyli nasze. Chociaż babkę ziemniaczaną jadłam i w Skierniewicach ale tam nazywano ją kugel. Każda gospodyni ma 
swoją recepturę na babkę ziemniaczaną .Tak się składa że miałam okazję jeść babkę w wielu miejscach naszego regionu , ale dla tej ,którą piekła moja teściowa nie dorównała żadna $\mathrm{z}$ nich. Po rannym obrządku w gospodarstwie teściowa rozpalała płytę w kuchni i ogrzewała duchówkę przez otwarcie szybra - czy jak to się tam nazywało. Ręcznie i tylko do babki przeznaczonej tarce tarkowała ziemniaki . (...) Gdy późnym popołudniem wracaliśmy z mężem z pracy wyjmowała garnuszek z duchówki odwracała do góry dnem i ech... to był moment nie do opisania, bo jak można przekazać ten zapach, widok unoszącej się pary i sam smak ? Gdy poszłam już na swoje piekłam babkę wedle przepisu teściowej, ale to nie była już ta sama w smaku, bo piekłam ją w blaszce i w elektrycznym piekarniku (tamże).

Autorka wpisu dzieli się dłuższą opowieścią o tym, jak umiejętność przyrządzania babki i kiszki ziemniaczanej przekazywana jest z pokolenia na pokolenie. Regionalne bywa więc legitymizowane nie tylko poprzez informacje podane w książkach kucharskich czy przekazane w blogach, ale również przez osobistą, ucieleśnioną wiedzę metis, wynikającą z naśladownictwa z wielokrotnego powtarzania pewnych czynności (rozumianą jako: „wiedza oraz szereg umiejętności praktycznych nabytych w toku reakcji na ciągle zmieniające się środowisko"; Scott 1998: 303). Jak widać, zarówno doznawanie przez rozmówców 'regionalności', jak i 'swojskości' jedzenia wynika też z osobistych relacji z osobami, które potrafią przyrządzić te dania.

\section{Widzialne i niewidzialne „superfoods” a tożsamość}

Jak widać z powyższych ustaleń, poszczególne kategorie potraw bądź produktów mają związek z poczuciem tożsamości terroir i przynależnością do miejsca. Można powiedzieć, że to układanka rozmaitych produktów tworzy kulinarną mapę „tożsamościową" tego miejsca. Tego rodzaju pokarmy, które są podstawą egzystencji, a zarazem skupiają na sobie w danej społeczności wiele znaczeń, Warren Belasco nazywa kulturowymi super foods (Belasco 2008: 16-17, 19-20).

Jednym z tych produktów jest właśnie ziemniak:

Wschodnia Polska, jak to mówią, ziemniakiem stoi, więc różne są z ziemniaków te potrawy robione. Ale ja sądzę, wie pan, że tutaj, ta wschodnia kuchnia była na tyle sugerowana tym, że tutaj jednak były biedniejsze regiony, niż to co na Południu, tam, na zachodzie Polski, były te rejony biedniejsze, więc tutaj, co się miało, to się gotowało, jak to się mówi. Moja babcia (...) mówiła, że (...), jak były wiosenne okresy, że no, było bardzo biednie, bo to już było tak, jak to się nazywało, przednówek. Jeszcze nie było następnych zbiorów, a stare już się kończyły. No to było bardzo ciężko, bo się gotowało na przykład zupę z lebiody. Z lebiody, tak, jak lebioda wschodziła, to się tak jak szczawiową na przykład zupę, no to wtedy, tak, 
co się miało, czy jakiś ziemniaczek, czy już tego, i się lebiodę. Nie jadłam tego, tyle wiem z opowiadań [29.07.2011, Harasimowicze, K, ok. 45, jej kuzynka ok. 40, jej mama ok. 70, gospodarz ok. 45].

Ziemniak w tych narracjach staje się metaforą przynależności do pewnego miejsca, ale też odwołaniem do swoich wiejskich (chłopskich) korzeni. Warzywo konotuje tu pewne wspólne doświadczenie ubóstwa i samowystarczalności, tak ważnej dla samookreślania się mieszkańców tych okolic:

Ludzie źle zrobili, że wyrzucili ziemniaki, a ziemniaki niestety są zdrowe, nie są kaloryczne, takie z wody, normalne, kiedyś dużo się jadło ziemniaków, na wsi i w ogóle, bo to było biedota, a teraz, ale ziemniak podstawa, bo w ziemniaku dużo witamin jest, potas jest (...), a teraz nie ma, bo zastąpili wszystko innymi rzeczami, ja ci powiem, po prostu z lenistwa nie chcą obierać ziemniaków. Bo to czasu brakuje, to się nie chce, to najlepiej to zasypał ryż czy makaron i spokój [27.07.2011, K, ok. 50, K, 14 (matka i córka)].

Nancy Ries, amerykańska antropolożka prowadząca badania w Rosji, pokazała, że również w tym kraju ziemniak jest czymś więcej niż tylko pokarmem, jest podstawą bytowania. Autorka uznaje kartoszkę za: „obiekt w świecie sprzężony z myśleniem zbiorowym (social mind) i w ten sposób będący nieredukowalnym medium myślenia o świecie i działania w nim" (Ries 2009: 182). Jej analiza pozwala dostrzec rozpad relacji pomiędzy państwem a społeczeństwem. Uprawa ziemniaka 'osadzona' jest nomen omen w pamięci historycznej i złożonym systemie wiedzy. Natomiast współcześnie w Rosji warzywo to wykorzystywane jest także w sposób symboliczny w narracjach dotyczących np. krytyki zachodniego konsumpcjonizmu czy tworzącej się opozycji miasto/wieś (Ries 2009). W podobnych kategoriach można interpretować przytoczone przeze mnie wypowiedzi o ziemniaku - jego spożycie staje się symbolem przynależności do wspólnoty smaku, ale także do wspólnoty osób podzielających pewne wartości - np. etos pracy (por. „teraz ludzie zrobili się zbyt leniwi, by obierać ziemniaki”). Jest więc, zarówno w przypadku Rosji, jak i Polski, wyznacznikiem dawnych oraz nowych tożsamości.

Kolejnym z lokalnych superfoods jest kapusta. Powszechność jej odzwierciedlają wypowiedzi, w których podkreśla się regularną konsumpcję tego warzywa, wpisanie go w codzienną ekonomię rodziny:

Kiedyś w niedzielę było zawsze coś z kapusty, tak mi się to kojarzy. To jest kapustny teren [23.07.2011, Dąbrowa Białostocka, M, ok. 55].

- Jakaś taka ulubiona potrawa?

K: Też nie mam. Nie, kapusta. (...) Pod każdą postacią. (...) Wszystko. Wszystko z kapusty [22.07.2001, Dąbrowa Białostocka, K, ok. 50]. 
K: O, moja córka była we Włoszech bawić dzieci. Bardzo zadowolona była. Tamta rodzina ją jak swoją przyjęła. (...) Bardzo jej się podobało. I dorobiła się. (...)

- I tamto jedzenie jej smakowało?

K: Tam to te makarony, spaghetti i do tego wszystkiego butelka wina na stole. Tam to w ogóle dużo alkoholu piją. Ale przez to wszystko takie prawdziwsze jest. (...) No bo to ich kultura. I oni to wino z własnej winnicy robią i tak przyzwyczajeni. U nas to tak nie ma. Chociaż mówią, że my to dużo tych ziemniaków i tej kapusty jemy, ale to taka tradycja nie jest do końca. Bo u nas to z tej biedy wojennej to, a obecnie to już zupełnie inaczej. (...) No mają, ale to z przyzwyczajenia i dla oszczędności. Ale najchętniej to by gotowe kupowali. Nie ma jakiegoś poszanowania dla dawniejszego [17.11.2011, Brzozowo, K, ok. 70].

Chciałabym w tym miejscu podkreślić wypowiedź rozmówczyni, która spożywanie kapusty wymienia jako tradycję, ale mówi, że „taka tradycja nie jest do końca". W przeciwieństwie do tradycji włoskiej, która miałaby wiązać się z przyjemnością, biesiadowaniem, lokalna tradycja kojarzy się raczej z biedą i brakiem wyboru.

Kapusta jest dla wielu mieszkańców okolic kolejnym produktem tak zwykłym i powszednim, że z jednej strony bywa pomijana, gdy pyta się o dania regionalne czy podlaskie itp. Do tej pory wiele rodzin na jesień zaopatruje się w kilka-kilkanaście (lub więcej) główek tego warzywa, kisząc je na różne sposoby. Kapusta jest niemal codziennie obecna w zimowym jadłospisie mieszkańców tych okolic. Choć produkt ten rzadko bywa kojarzony z typowymi „regionalnymi daniami", łączy się go w narracjach z tym regionem i właściwym dla niego sposobem życia (wiejskim). W powyższych wypowiedziach widoczne jest, że produkt ten nabiera rangi symbolu przywiązania do tradycji. Ostatnia wypowiedź jest szczególnie znacząca, ponieważ skonfrontowane w niej zostają dwa rodzaje praktyk jedzeniowych, a zarazem dwa style życia - ten właściwy „obcym” - w tym przypadku Włochom poznanym na emigracji, którzy spożywają dużo alkoholu, i ten „swój”, znany, który charakteryzuje poszanowanie dla dawniejszego i przyzwyczajenie do oszczędności.

Przypuszczam jednak, że najważniejszym superfoodem dla lokalnych społeczności jest mięso, w szczególności mięso i produkty wieprzowe. Sposób budowania tożsamości (płciowej, lokalnej, „swojskiej”) na podstawie konsumpcji i produkcji wieprzowiny opisałam szczegółowo w innej pracy (Mroczkowska 2014a), w tym miejscu chciałabym podkreślić tylko rolę tego produktu w tworzeniu pewnej „wschodniej” i polskiej wspólnoty wyobrażonej. Poniższa wypowiedź zwraca uwagę właśnie ze względu na aspekt budowania wspólnoty ogólnokrajowej ze względu na sposób jedzenia:

- A z jakich mięs się robi wyroby? [Pytanie dotyczyło „kuchni podlaskiej” przyp. J.M.]

K: U nas w Polsce to z wieprzowiny przeważnie [28.03.2012, Małyszówka, K, ok. 60]. 
Czy na przykład poniższa wypowiedź:

\begin{abstract}
Zresztą ja byłam za granicą, spotykałam się z ludźmi ze Sri Lanki, Filipin, Peru. Chińczyków miałam. (...) To sami ludzie, takie same mają serca. Może inaczej jedzą. Pracowałam w Irlandii i widziałam, jak szczury jedli. No tak, ale to jest normalne. Dla nich tak. Ale no tak jak oni by nie zjedli wieprzowiny, tak my nie zjemy szczura. (...) W pakistańskiej restauracji pracowałam, i był taki z tyłu, był taki mur, i przy tym murze porobili takie domki z metalu, i wyobraź sobie, tam jak szczur wleciał, to on żywcem go zostawiał. A potem patrzę, widzę, a w piecu na takich długich drągach folią aluminiową owinięte, i oni to pieką. Ale słuchaj, dla nich to było normalne, a zresztą to wtedy był post. To jest tak, że nie mogą jeść mięsa, chyba że złapią samodzielnie.

M: (...) W każdym miejscu są inne kultury.

K: Tak że tolerancja musi być, ale Polacy chyba jeszcze tak nie mają. To znaczy bliżej Warszawy to chyba bardziej [13.11.2011, Szuszalewo, M, ok. 30, K, ok. 56 (syn i matka)].
\end{abstract}

Jak widać, sposób jedzenia mięsa i tabu żywnościowe z nim związane są jednymi z najsilniej różnicujących wyznaczników tożsamości ${ }^{7}$.

Tak jak pisałam, istnieje wyraźna kategoria potraw, które są wymieniane jako "pochodzące stąd”, „miejscowe" bądź „z Podlasia”. Są więc one w sposób dosyć jednoznaczny przypisane pewnemu regionowi, ale nie do końca wiadomo, z która religią, etnicznością czy kulturą należy je identyfikować. Do takich dań należą: kiszka ziemniaczana, babka ziemniaczana, kutia, farszynki (pulpety z gotowanych ziemniaków nadziewane farszem $\mathrm{z}$ mięsa, smażone $\mathrm{w}$ panierce), przecieraki (kluski z tartych ziemniaków/mąki/jajka). Wokół tych dań - w większości ziemniaczanych - tworzą się rozmaite konflikty i negocjacje tożsamościowych granic. Ludzie zadają sobie pytania (i próbują na nie odpowiedzieć) o pochodzenie potrawy, o jej przynależność do danej grupy narodowej czy religijnej. $\mathrm{W}$ negocjacjach tych widoczna jest chęć zawłaszczenia symbolicznego potrawy i emocjonalne przywiązanie do niej. Widoczna jest również niepewność co do jej statusu: czy dana potrawa w kuchni innego narodu może być jednocześnie uznana za podlaską. Daje się zaobserwować silna tendencja do wyznaczania granic, tęsknoty za autentycznością i bezdylematowym posiadaniem.

W refleksji nad związkiem jedzenia i tożsamości należy odróżnić produkty, który rozpoznawane i postrzegane są przez ludzi jako „lokalne”, ,"stąd" lub „podlaskie", od tych, które choć są istotnym elementem lokalnej specyfiki kulinarnej, pozostają w dużej mierze niezauważone przez samych mieszkańców tego regionu. Zaczyna się je spostrzegać dopiero w wyniku kontaktu/zderzenia z innym stylem życia, w którym dany produkt zostaje uznany za właściwy lokalnemu

\footnotetext{
${ }^{7}$ Owo „u nas" jest w odniesieniu do przestrzeni rozumiane szeroko: ludzie obejmują mentalnie większą przestrzeń jako „swoją" niż na przykład w mieście. Powszechne są w opisywanej społeczności regularne wyjazdy w celach towarzyskich, rodzinnych i religijnych do miejscowości oddalonych nawet o kilkadziesiąt czy sto kilometrów.
} 
kontekstowi. Do tej pierwszej kategorii - produktów emicznie określanych jako właściwe dla tego miejsce lub regionu - włączane są potrawy świąteczne lub potrawy ",codzienne”, lecz wyjątkowo pracochłonne. Ta druga kategoria wpisana jest zaś silnie w codzienność i prostotę zwykłego dnia.

I tak na przykład od lat, gdy jeździłam w te okolice, uderzała mnie ogromna ilość uprawianych słoneczników; ich dojrzałe kwiatostany trzymano potem na balkonie, wyłuskiwano z nich pestki, robiąc z nich zapasy na całą zimę. Konsumpcja pestek właściwa jest przestrzeni publicznej - należy bowiem pozbyć się łupinki, a to najłatwiej zrobić na podwórku. Pestki zagryza się, jadąc samochodem (i wypluwając łupinki przez okno), siedząc na ławkach pod klatką, na schodach prowadzących na stadion, $\mathrm{w}$ centrum miasta. $\mathrm{Z}$ ich konsumpcją łączy się także pewna estetyka. Łupinki widoczne są $\mathrm{w}$ przestrzeni miasteczka, ich skupiska są rozpoznawalnymi znakami miejsc spotkań towarzyskich. Rzucanie ich pod nogi jest nieodłącznym elementem tych praktyk. Swoisty jest sposób: najczęściej rozgryzane są między zębami a nasiono wyciskane z łupinki. Czasem - często w przypadku kobiet - dochodzi dodatkowy element: po rozgryzieniu otwiera się je palcami, zręcznie wyjmując nasionko. Gryzienie ich, wyrzucanie odbywa się w pewnej pozie zrelaksowania, swobodnego zawłaszczania i znaczenia przestrzeni, w której się osoba znajduje.

O pestkach mówi się jako o „nawyku” - rozmówcy posługują się tym pojęciem. Pestki są swoistymi „pokarmami-używkami”, mieszczą się w kategorii produktów, które „wciągają", obok orzeszków w łupinkach, ciasteczek, chipsów itp. Popularne są także kupowane solone pestki w łupinkach z Biedronki. Jedna z moich rozmówczyń mówiła mi, że zniszczyła zęby na pestkach i dlatego przestawiła się z konieczności na „worki łuskanych” z Biedronki. Widać więc, w jaki sposób nawyki zostają zapisane w ciałach mieszkańców i w ich przestrzeni. Stają się pewnym znakiem ich tożsamości, ale wydaje się, że znakiem czytelnym raczej dla przybysza z zewnątrz.

\section{Temporalność smaku}

W kulturze masowej funkcjonuje mitologizujące i stereotypizujące przeświadczenie, że jedzenie wiejskie funkcjonuje w niezmienionej formie od dawna, a jego korzenie sięgają czasów odległych. Tak naprawdę, jak dowiodła tego Rachel Laudan, tradycja - w szczególności kulinarna - bywa tworzona niezwykle szybko. Badaczka pokazała to poprzez analizę wydawnictw przepisów kulinarnych z kilkudziesięciu lat, w których zupełnie nowe dania $\mathrm{z}$ wybranego regionu opisywane były w kolejnych wydaniach jako pradawne (Laudan 2001). Owa odwieczność nie powinna być traktowana jako fakt historyczny, a raczej jako kategoria potoczna budująca przekonanie o trwałości wzorców kulinarnych.

Podobny trend łatwo jest zauważyć również w opisywanej przeze mnie społeczności. Dania, które jeszcze kilka czy kilkanaście lat temu nie były znane, obecnie określane są jako „stare”. O melbie, cieście przygotowywanym na zimno 
z biszkoptów i galaretek, autorka internetowego bloga o kuchni lokalnej (okolic Dąbrowy Białostockiej) pisze w ten sposób: „Delikatne ciasto na bazie twarożku, który sami przygotowujemy z mleka, jajek i kwaśnej śmietany lub kwaśnego mleka. (...) Bardzo stary przepis, który znalazłam w swoich zapiskach sprzed 20 lat"8. Jedna z osób komentujących tę wypowiedź (pochodząca również z tych okolic) odpowiada następująco, potwierdzając zakorzenienie przepisu w społeczności: „Również mam melbę w starych przepisach. Kiedyś robiłam ją często dla dzieci, z tym że na herbatnikach, które były bardziej dostępne. (...) Pani Halinko pani przepisy nie tylko robią tak zwanego smaka, ale i przywołują wspomnienia :)".

Uwidacznia się tu pewien niezwykły aspekt kulinariów - elastyczność związanych z nimi praktyk i wiedzy, a także umiejętność szybkiego zakorzenienia się w danej społeczności i szerzej w danej przestrzeni. Melba, deser, który zyskał popularność w społeczności w latach dziewięćdziesiątych, dwadzieścia lat później opisywany jest jako znaleziony w „starych przepisach”. Ponadto „, autentyczności" i mocy zakorzenienia nadaje mu fakt, że przygotowywany był przez inne kobiety w rodzinie. Przekaz międzypokoleniowy i więź ze starszymi kobietami "przebłyskująca" w przekazanych przepisach sprawia, że melba zyskuje w społeczności legitymizację „swojego" jedzenia.

Jak rozpatrywać podobne obserwacje w obliczu spostrzeżenia Rocha Sulimy: „kody kulinarne, tak jak muzyczne, należą do najbardziej trwałych wyznaczników tożsamości" (Sulima 2000, s. 152)? Moim zdaniem nie należy pochopnie odrzucać zawartej tu myśli, gdyż na pewnej płaszczyźnie nie musi ona być sprzeczna z zaobserwowaną przeze mnie zmiennością kodów kulinarnych. Postuluję, że choć w wymiarze czasowym kody są niezwykle zmienne, to na płaszczyźnie deklaracji uważane są za trwałe. Ponadto są one w tym sensie trwałym wyznacznikiem tożsamości terroir, jako że kody ucieleśnione (podobnie jak muzyczne) są niezwykle mocno zakorzenione w człowieku i jego środowisku. Raz pasujący i aprobowany smak niezwykle trudno jest odrzucić (pokazują to dobitnie przykłady kuchni migracyjnych, kiedy np. spożycie chleba staje się wyznacznikiem polskości, por. Rabikowska 2010).

Tożsamość jedzeniowa rolnika opiera się w dużej mierze na odwołaniach do dawniejszego, prostszego i biedniejszego sposobu życia:

M: Jak to się mówi, nasza dawna solona słonina z przyprawami najlepsza, jak to się mówi, zagrycha do jakiegoś trunku. Stąd wyciągnęli to, że jak jakaś flaszka jest na stole, to jak słonina jest, to nie ma biedy [15.11.2011, Grabowo, M, ok. 55, K, ok. 48 (mąż i żona)].

Zarówno wspominanie owego jedzenia, odtwarzanie go i smakowanie pełni rozmaite funkcje społeczne i jest przez różne osoby używane w celu podkreślenia specyfiki człowieka roli, etosu pracy, a nawet swoistej wyższości moralnej. W antropologii jedzenia ów sposób odwoływania się do jedzenia z przeszłości

${ }^{8}$ Zob. https:/ /isokolka.eu/blogi/154-smakolyk/7497-melba-blog [dostęp: 24.11.2019]. 
nosi miano „nostalgii jedzeniowej” (por. Holtzman 2006). Nostalgię jedzeniową można rozumieć na dwa sposoby; po pierwsze, jako powtórne doświadczenie i odtwarzanie emocjonujących chwil z przeszłości - taka perspektywa jest najczęstsza i wymiar ten jest zdecydowanie istotny dla zrozumienia tego, jak pojęcie i zjawisko „jedzenia dawnego" ustanawia konkretne relacje pomiędzy ludźmi lub jest używane, by dane relacje ustanowić. Zawiera w sobie również wiele wartości charakterystycznych dla społeczności związanych z wsią i rolnictwem (np. wynikających z zasady gościnności, gospodarności czy przywiązania do robienia zapasów itp.).

Nostalgia jedzeniowa obecna jest również w opowieściach dotyczących migracji - wtedy jedzenie/smak stają się łącznikiem z domem, tutejszością, ,swojskością":

R: A mówił, że brakuje mu polskiego jedzenia tam?

M: O Jezu, pewno [śmiech]. Jak zajechałam tam do nich, to od razu na pierwsze mówi: „Mamo, ugotuj tatowej zupy”, a taka tatowa zupa to już mój mąż, a jego tato to lubił, że fasola z pęcakiem gotowana, wrzucona kostka mięsa, ni bielona taka, i bez ziemniaków, i marchewka i tam jeszcze pietruszka, i tego. I to tak gotowano. To nazwał to tatową zupą, po dzisiejszy dzień tatowa zupa [śmiech]. A wiecie co, amerykańskie jedzenie, a tutaj to jest różnica. Ja, żeby nie polskie sklepy tam, toby z głodu umarła. (...) A tam przestraszne jedzenie, wszystkie takie nasączone, takie jakieś sztywne, bezsmakowe, no całkowicie. I teraz tak o wstręt mam do tego, że jak nie przerobię po swojemu, no to mnie tylko jedna kiełbasa smakuje tutaj w Dąbrowie [28.07.2011, Szuszalewo, K72].

Wspomnienia o jedzeniu, a zarazem odtwarzanie dawnego „swojego" jedzenia stają się więc „sposobem na zachowanie tożsamości, które obecnie postrzegane są za zagrożone przez migracje, mobilność czy miejską kulturę masową" (Belasco 2008: 27).

\section{Podsumowanie}

Powyższe ustalenia potwierdzają siłę, jaką ma jedzenie, sposób jego konsumpcji i produkcji, na tworzenie się tożsamości terroir. Wynika to zarówno ze wspólnotowości wpisanej w jego produkcję i konsumpcję, ale widoczne jest także w samych praktykach narracyjnych dotyczących jedzenia. Jedzenie wiąże więc ludzi z regionem, ze środowiskiem, z lokalnością, domem. Co interesujące, nie zawsze same kategorie, takie jak podlaskość czy Wschód, są kojarzone z wyróżniającymi (dla przybysza z zewnątrz) ten region potrawami. Wraz z przypisaniem pewnych potraw (takich jaki kiszka ziemniaczana, babka ziemniaczana) czy produktów (ziemniak, kapusta, słonina) do sposobu jedzenia właściwego dla lokalnych mieszkańców dokonuje się także pewna społeczna, a czasem i moralna ocena tego rodzaju konsumpcji. Jedzeniu zostają przyporządkowane określone 
wartości, charakterystyczne, zdaniem lokalnych mieszkańców, dla tego terenu i dla życia rolnika. Są nimi: samowystarczalność, etos pracy rąk własnych, wspólnotowość (wyrażająca się m.in. poprzez dzielenie się jedzeniem i jego wymianę w społeczności), poszanowanie dla tradycji, oszczędność, rodzinność, a nawet więź z krajem i patriotyzmu - to ostatnie staje się wyraźne szczególnie w kontekście migracyjnym (szerzej rozwijam ten wątek w [Mroczkowska 2014b]).

Anna Wieczorkiewicz pisze:

z jednej strony dania narodowe, regionalne i etniczne kreolizują się, ulegają umiędzynarodowieniu, stając się całkiem nowym produktem wrzuconym do globalnego gara; z drugiej natomiast wzorce kulinarne funkcjonują jako symbole tożsamości, jako środek praktyk integrujących grupy ludzkie o różnym charakterze. Lokalną kulturę gastronomiczną traktuje się jako emblemat ogólnie rozumianego stylu życia, nadający się do wykorzystania przy tworzeniu własnego wizerunku na światowej scenie (Wieczorkiewicz 2004: 205).

Z kolei, jak twierdził historyk żywienia Massimo Montanari, dopiero w ostatnich kilkunastu czy kilku latach jedzenie regionalne nabrało kulturowego statusu ikony, a kwestie związane z jedzeniem globalnym i regionalnym stały się w naukach społecznych palącym tematem (Montanari 2006: 83). Ta zmiana postrzegania jedzenia regionalnego wynika, jego zdaniem, z paradoksu globalizacji i jego społecznej ekspansji. W zdefragmentowanym świecie starożytnym i średniowieczu celem, jak pisze autor, było stworzenie uniwersalnego (przynajmniej dla warstw, które było na to stać) modelu konsumpcji. Obecnie zaś, we współczesnej „globalnej wiosce”, pierwszą wartością jest zróżnicowanie i wielość. Tym należy tłumaczyć glokalizację, czyli silne tendencje lokalne będące drugą stroną uniwersalizmu globalizacyjnego (Montanari 2006). Lokalne jedzenie, uosobione w emicznej metaforze jedzenia „swojego”, wyraża więc „lokalne” wartości kulturowe, „wiążąc ze sobą ludzi i ziemię land/obszar/terytorium w zrównoważonych ekologicznie relacjach" (Egan et al. 2006: 31) i tworząc tożsamość terroir.

\section{Literatura}

Appadurai, A. (1988). How to Make a National Cuisine: Cookbooks in Contemporary India. Comparative Studies in Society and History, 30(1), 3-24.

Belasco, W. (2008). Food. Key Concepts. Oxford and New York: Berg.

Bérard, L., Marchenay, P. (1995). Lieux, temps et preuves: la construction sociale des produits de terroir. Terrain, 24, 153-164.

Bourdieu, P. (1972). Outline of a Theory of Practice. Transl. R. Nice. Vol. 16. Cambridge: Cambridge University Press.

Burszta, W.J., Kuligowski, W. (2005). Fast food, slow food, smalec babuni. W: Sequel. Dalsze przygody kultury w globalnym świecie. Warszawa: Warszawskie Wydawnictwo Literackie MUZA S.A. 
Camp, Ch. (2003). Foodways. W: S.H. Katz (ed.), Encyclopedia of Food and Culture, t. 2: Food Production to Nuts. New York: Thomson and Gale, 29-31.

Clifford, J. (2000). Kłopoty z kultura. Dwudziestowieczna etnografia, literatura i sztuka. Warszawa: Wydawnictwo KR.

Demosier, M. (2011). Beyond terroir: territorial construction, hegemonic discourses, and French wine culture. Journal of the Royal Anthropological Institute (N.S.), 17, 685-705.

Dobrowolski, K. (1966). Studia nad życiem społecznym i kultura. Wrocław-Warszawa-Kraków: Wydawnictwo PAN, Zakład Narodowy im. Ossolińskich.

Egan, J.A., Burton, M.L., Nero, K.L. (2006). Building lives with food: Production, circulation and consumption of Food in Yap. W: R. Wilk (ed.), Fast Food/slow Food: The Cultural Economy of the Global Food System. Lanham: Altamira Press, 31-48.

Fonte, M. (2008), Knowledge, Food and Place. A Way of Producing, a Way of Knowing. Sociologia Ruralis, 48(3), 200-222.

Holtzman, D.J. (2006). Food and Memory. Annual Review of Anthropology, 35, 361-378.

Jasiewicz, Z. (1987). Tradycja. Hasło w: Z. Staszczak (red.), Stownik etnologiczny. Warszawa: Państwowe Wydawnictwo Naukowe.

Kleśta-Nawrocka, A., Kleśta-Nawrocki, R. (2016). Rekonstrukcje menonickich specjałów. W: A. Pabian, M. Targowski (red.), Olędrzy - osadnicy znad Wisty. Sąsiedzi bliscy i obcy. Toruń: Fundacja Ośrodek Inicjatyw Społecznych ANRO, s. 157-172.

Kuper, A. (2006). Kultura. Model antropologiczny. Kraków: WUJ.

Laudan, R. (2001). A plea for culinary modernism. Why we should love new, fast, processed food. Gastronomica: The Journal of Food and Culture, 1(1), 36-44.

Montanari, M. (2006). Food is Culture. New York : Columbia University Press.

Mroczkowska, J. (2014a). Transformacja życia w śmierć, a śmierci w pokarm. Społeczny wymiar świniobicia w podlaskiej wsi. Maska. Magazyn antropologiczno-społeczno-kulturowy, numer Zwierzę, 22. Kraków: AT Wydawnictwo, 204-213.

Mroczkowska, J. (2014b). "Our food". Foodways and identity of Polish returning migrants from the United States. The Americanist, Thinking food: the functions of food in American culture and society, 29, 139-159.

Olędzki, J. (1961). Doroczne pieczywo obrzędowe pótnocno-wschodniej Polski. „Konteksty. Polska Sztuka Ludowa", 15(1), 3-23.

Preston-Werner, T. (2009). Gallo Pinto: Tradition, Memory, and Identity in Costa Rican Foodways. Journal of American Folklore, 122(483), 11-27.

Rabikowska, M. (2010). The Ritualisation of Food, Home and National Identity among Polish Migrants in London. Social Identities, 16(3), 337-339. Special issue, ed. M. Rabikowska.

Ries, N. (2009). Potato Ontology: Surviving Postsocialism in Russia. Cultural Anthropology, 24(2), 181-212.

Sahlins, M. (1972). Stone Age Economics. Chicago, New York: Aldine Atherton Inc.

Scott, J. (1998). Seeing Like a State: How Certain Schemes to Improve the Human Condition Have Failed. Yale: Yale University Press.

Shils, E. ([1981] 1984). Tradycja, tłum. J. Szacki. W: Tradycja i nowoczesność, wybór J. Kurczewska, J. Szacki. Warszawa: Czytelnik.

Straczuk, J. (2006). Cmentarz i stót. Pogranicze prawostawno-katolickie w Polsce i na Białorusi. Wrocław: Wydawnictwo Uniwersytetu Wrocławskiego.

Sulima, R. (2000). Antropologia codzienności. Kraków: Wydawnictwo Uniwersytetu Jagiellońskiego.

Waszczyńska, K. (2014). Wokół problematyki tożsamości. Rocznik Towarzystwa Naukowego Płockiego, 6, 48-73. 
Wieczorkiewicz, A. (2004). Cały świat w zasięgu smaku. O projektach doświadczeń kulinarno-turystycznych. W: M. Jacyno, A. Jawłowska, M. Kempny (red.), Kultura w czasach globalizacji. Warszawa: Wydawnictwo IFIS PAN.

Zubaida, S., Tapper, R. (2000). A Taste of Thyme: Culinary Cultures of the Middle East. London: Tauris Parke Paperbacks.

\section{ABSTRACT \\ Regional, local or 'our' food. The identity dimension of foodways in the Polish Podlachia region}

This article explores the connections between identity and foodways of farmers and small-town inhabitants in Eastern Poland, showing that food may serve as a strong metaphor of identity and the way of building ties and upholding community. The main food idioms are linked with the idea of "our" food, food which is local, familiar and familial, and the notions based on the connection with a certain region (terroir), along with with its history, people, environment, taste qualities. These are embedded in the locality and connect ideas of food, health, relationality and moral values (work), which are key building blocks of local identity.

Keywords: foodways, Poland, countryside, community, „our" food, identity, tradition, terroir, Podlachia region 